\title{
Glutaredoxin 2 Reduces Both Thioredoxin 2 and Thioredoxin 1 and Protects Cells from Apoptosis Induced by Auranofin and 4-Hydroxynonenal
}

\author{
Huihui Zhang, ${ }^{*}$ Yatao Du, ${ }^{*}$ Xu Zhang, Jun Lu, and Arne Holmgren
}

\begin{abstract}
Aims: Mitochondrial thioredoxin (Trx) is critical for defense against oxidative stress-induced cell apoptosis. To date, mitochondrial thioredoxin reductase (TrxR) is the only known enzyme catalyzing Trx 2 reduction in mitochondria. However, TrxR is sensitive to inactivation by exo/endogenous electrophiles, for example, 4hydroxynonenal (HNE). In this study, we characterized the mitochondrial glutaredoxin 2 (Grx2) system as a backup for the mitochondrial TrxR. Meanwhile, as Grx2 is also present in the cytosol/nucleus of certain cancer cell lines, the reducing activity of Grx2 on Trx1 was also tested. Results: Glutathione alone could reduce oxidized Trx2, and the presence of physiological concentrations of Grx2 markedly increased the reaction rate. HeLa cells with Grx2 overexpression (particularly in the mitochondria) exhibited higher viabilities than the wild-type cells after treatment with TrxR inhibitors (Auranofin or HNE), whereas knockdown of Grx2 sensitized the cells to TrxR inhibitors. Accordingly, Grx2 overexpression in the mitochondria had protected Trx2 from oxidation by HNE treatment, whereas Grx2 knockdown had sensitized Trx 2 to oxidation. On the other hand, Grx 2 reduced Trx 1 with similar activities as that of Trx2. Overexpression of Grx 2 in the cytosol had protected Trx 1 from oxidation, indicating a supportive role of Grx2 in the cytosolic redox balance of cancer cells. Innovation: This work explores the reductase activity of Grx 2 on Trx $2 / 1$, and demonstrates the physiological importance of the activity by using in vivo redox western blot assays. Conclusion: Grx 2 system could help to keep Trx2/1 reduced during an oxidative stress, thereby contributing to the anti-apoptotic signaling. Antioxid. Redox Signal. 21, 669-681.
\end{abstract}

\section{Introduction}

$\mathbf{T}$ HE THIOREDOXINS (Trxs) and glutaredoxins (Grxs) belong to the Trx superfamily of thiol-disulfide oxidoreductases (25). Each redoxin is the electron receptor of their redox system, and the effector of the downstream redox regulations. In mammalian cells, the cytosolic Trx system composed of nicotinamide adenine dinucleotide phosphate (NADPH), thioredoxin reductase 1 (TrxR1), and Trx1, whereas the Grx system is formed by NADPH, glutathione reductase (GR), glutathione (GSH), and Grx1. Relatively independent of the cytosolic milieu, the mitochondria have their own Trx and Grx systems, consisting of NADPH, TrxR2 (22), and Trx2 (38) or NADPH, GR, GSH, and Grx2 (28), respectively.

\section{Innovation}

In mammalian cells, the thioredoxins (Trxs) need to be in the reduced state to have antioxidant and anti-apoptotic effects. This study suggests that glutaredoxin 2 (Grx2) could work as a backup for thioredoxin reductase (TrxR) in keeping Trx reduced when cells are encountering exo/ endogenous electrophiles, which are potent inhibitors of TrxR. Particularly in mitochondria, which are the main source of cellular reactive oxygen species, Grx 2 here is the first and only hitherto found enzyme that can work as a backup for the reduction of Trx2. This finding may further explain the critical role of Grx2 in the redox signaling of cell survival/apoptosis. 
The Trx and Grx systems play critical roles in providing reducing equivalent for DNA synthesis, maintaining cellular thiol-redox homeostasis, defense against oxidative stress, controlling protein folding, and regulation of cell growth/ apoptosis $(5,6,19,23)$. Although they share some common functions in the above-mentioned processes, the two systems also differ in their selection of substrate groups and their affinity and activity to the substrates, thereby take effects in different regulatory checkpoints of the physiological pathways. The two systems may support each other's functions but could not substitute for each other, probably due to their respective unique functions.

In general, Trxs are more active in catalyzing the reduction of intra- or interchain disulfides of protein substrates. Trxs are specific and super-fast electron donor for peroxiredoxins (Prxs), which are one of the major players in the elimination of hydrogen peroxide $\left(\mathrm{H}_{2} \mathrm{O}_{2}\right)$, both in the cytosol (Prx I, II) and in the midochondria (Prx III, V) (36). Trxs regulate the activity/activation of many important transcription factors [e.g., nuclear factor kappa-light-chain-enhancer of activated $\mathrm{B}$ cells $(\mathrm{NF}-\kappa \mathrm{B})(32)$, activator protein 1 (AP-1) (18)] or apoptosis signaling factors $[e . g$., apoptosis signal-regulating kinase 1 (ASK-1) (37) or phosphatase and tensin homolog (PTEN) (33)] through modulating the redox-regulatory disulfides of the protein. Reduced Trx is usually a factor and indicator of cell survival, whereas oxidized Trx being a factor and indicator of cell death. Knock out of either Trx 1 or Trx 2 will cause embryonic lethality in mice, and the fibroblasts from these mice are not viable $(31,34)$, indicating that both Trx 1 and Trx 2 are required to be functional for mammalian cell growth and survival.

Apart from the common functions with Trxs, Grxs are specifically active in catalyzing the (reversible) deglutathionylation of their protein substrates at the expense of GSH. Protein S-glutathionylation is an important reversible posttranslational modification that works as thiol-redox signaling for many cellular events, including apoptosis (2). Grx2 was discovered in 2001 (28), with only $34 \%$ sequence identity with Grx1. Compared to Grx1, Grx2 has higher affinity toward the S-glutathionylated protein substrates, but with lower turnover rates (20). Grx2 is not inactivated by oxidation (28), exhibiting better resistance in an oxidative milieu. Grx 2 has been found to catalyze the reversible oxidation and glutathionylation of mitochondrial membrane thiol proteins (3), responding to both mitochondrial redox signals and oxidative stress. Grx 2 overexpression could prevent $\mathrm{H}_{2} \mathrm{O}_{2}$-induced apoptosis by protecting complex I activity in the mitochondria (42). Also, Grx2 could detoxify the mutant superoxide dismutase 1 (SOD1) in mitochondria by preventing its aggregation (14). HeLa cells with Grx2a overexpression are more resistant to the oxidative stress-inducing agents doxorubicin (Dox) and phenylarsine oxide due to reduced cytochrome c release (12), whereas siRNA-induced silencing of Grx 2 sensitized HeLa cells to Dox treatment (26). These facts imply a critical role of mitochondrial Grx2 in cell survival/apoptosis.

Remarkably, cross talks of the Trx and Grx systems do exist and need to be clarified to have a better view of the redox regulation. Examples of the cross talking include the following: Trx was found to reduce GSSG, thereby having the potential to regenerate GSH in GR-deficient cells (21). Depletion of GSH by buthionine sulfoximine (BSO) results in Trx2 oxidation (45). A previous study in our laboratory revealed that Grx 2 could use the reducing equivalent from TrxR (20). Later in our study, we found that Grx system could work as a backup for TrxR1 in the cytosol, keeping Trx1 reduced when TrxR1 were inhibited (11). However, it is still not known if there is any backup enzyme system that helps to keep Trx 2 reduced in the mitochondria. In this study, we have analyzed the activities of Grx 2 system to reduce Trx2, as well as Trx1, by which Grx2 system may work as a backup for TrxR. We have also applied Grx 2 overexpression as well as knockdown in HeLa cells and challenged the cells with TrxR inhibitors and checked the cell viabilities and redox states of Trx2 and Trx1 in vivo, in searching of the physiological significance of this reducing activity of Grx 2 on Trx2/1.

\section{Results}

\section{Grx2 system as a reductant of Trx2}

The active site oxidized hTrx $2\left(\mathrm{hTrx} 2-\mathrm{S}_{2}\right)$ was prepared by incubation with insulin and confirmed by redox urea-polyacrylamide gel electrophoresis (urea-PAGE) (Fig. 1A). The concentration of GSH in the mitochondrial matrix is in the millimolar range, and even up to $14 \mathrm{~m} M$ considering the volume of the matrix (29). With Trx $2-\mathrm{S}_{2}$ as substrate, we have tested the reducing rates of a series of GSH concentrations on Trx2. As shown in Figure 1B, the reducing rate had an exponential increase as the concentration of GSH increases, consistent with the stoichiometry of the reaction (two molecules of GSH reduced one molecule of oxidized Trx2). To test the reductase activity of Grx 2 on Trx2, we used GSH concentrations of 1 and $10 \mathrm{~m} M$, respectively, and different concentrations of Grx2 to simulate the physiological levels of mitochondrial Grx system. Figure $1 \mathrm{C}$ shows the reaction curves at the GSH level of $1 \mathrm{~m} M$. The addition of $0.05,0.2$, and $0.5 \mu M$ Grx 2 resulted in a concentration-dependent increase of the reaction rate, with the activity of 0.2 and $0.5 \mu M$ Grx 2 comparable to that of 0.8 and $1.1 \mathrm{n} M$ TrxR, respectively. Figure 1D shows the reaction curves under the GSH concentration of $10 \mathrm{~m} M$. Ten micromolars of GSH alone gives a rate similar to that of $2 \mathrm{n} M$ TrxR. The addition of 0.05 and $0.2 \mu M$ Grx2 increased the rates to be comparable to the activities of 3.6 and $6.1 \mathrm{n} M$ TrxR, respectively.

\section{Grx2 system as a reductant of Trx1}

Specifically within testis and many kinds of cancer cells, Grx2 presents not only in mitochondria but also in the cytosol (27). It is thus interesting to know if Grx2 could work as a reductase of Trx1. Trx1 has five cysteines (Cys), among them three are structural, the other two (Cys32 and Cys35) form the active site (16). The fully reduced Trx1, with all its five cysteines reduced, designated as $\operatorname{Trx} 1-(\mathrm{SH})_{2}$, transform to the active site oxidized form $\left(\operatorname{Trx} 1-\mathrm{S}_{2}\right)$ by reducing substrate protein disulfides. The Trx $1-\mathrm{S}_{2}$ was prepared as described in the Materials and Methods section and confirmed by redox urea-PAGE (Fig. 2A) and used as substrate for Grx2 system reduction assay. The reaction curves under the GSH concentration of $1 \mathrm{~m} M$ are shown in Figure 2B. The addition of increasing concentrations of Grx 2 resulted in increasing reaction rates. The activity of $0.2 \mu M$ Grx 2 is comparable to that of 1 $\mathrm{n} M$ TrxR, whereas the activity of $0.5 \mu M$ Grx 2 is comparable to that of $2 \mathrm{n} M$ TrxR. Figure 2C shows the reaction curves under the GSH concentration of $10 \mathrm{~m} M$. The activity of $10 \mathrm{~m} M$ 

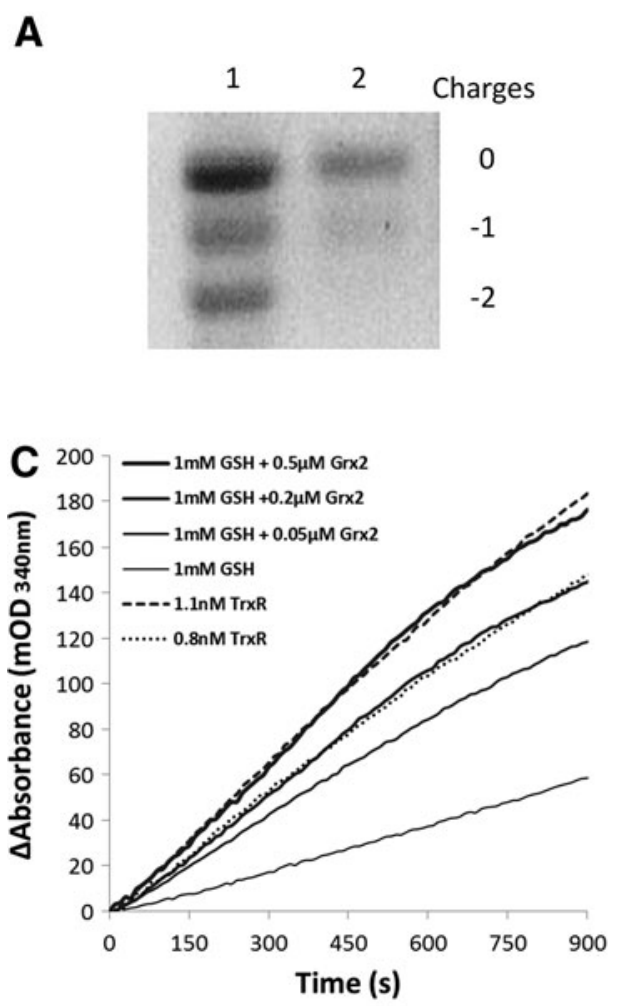
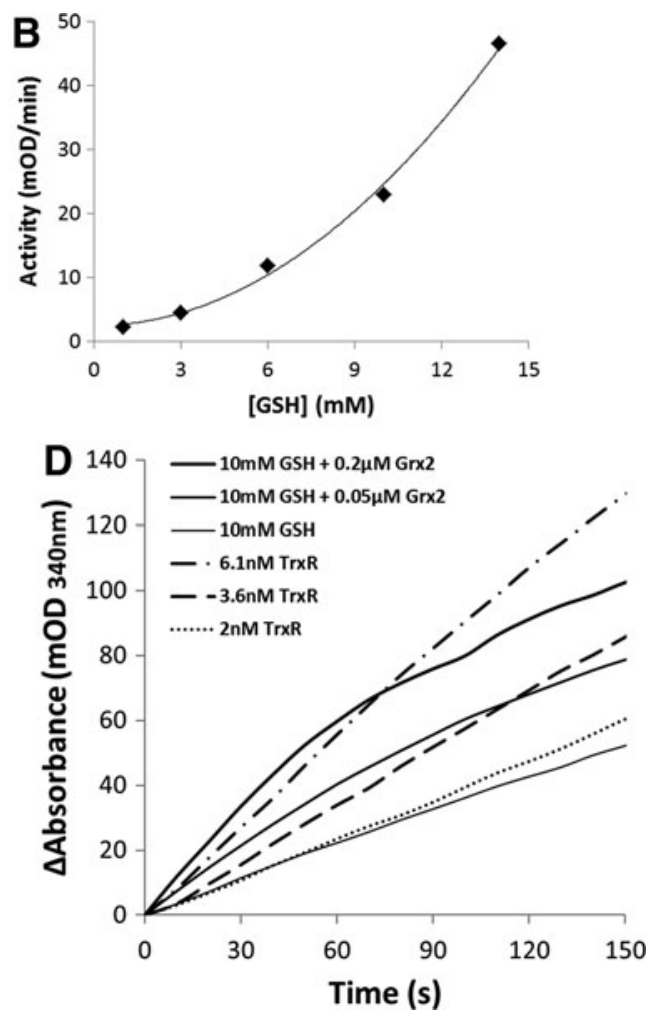

FIG. 1. The reduction of Trx2 by Grx2 system. (A) Trx2-S was prepared as described in the Materials and Methods section and confirmed by redox urea-PAGE. Lane 1: mobility standard. Lane 2: Trx2-S 2 . (B) Reduction of Trx2-S $\mathrm{S}_{2}$ by GSH. For the GSH reduction assay, $6 \mu \mathrm{g} / \mathrm{ml} \mathrm{GR}, 0.2 \mathrm{mM} \mathrm{NADPH}$, and $25 \mu M \operatorname{Trx} 2-\mathrm{S}_{2}$ were added to cuvettes in the presence of 1,3, 6,10 , and $14 \mathrm{~m} M \mathrm{GSH}$. The absorbance at $340 \mathrm{~nm}$ was followed, and the linear part of the reactions was used to determine the reaction rates. (C) For the Grx2 reduction assay, $6 \mu \mathrm{g} / \mathrm{ml}$ GR, $0.2 \mathrm{mM}$ NADPH, $1 \mathrm{~m} M$ GSH, $25 \mu M$ Trx2-S ${ }_{2}$, and increasing amounts of Grx2 (the solid lines thickening from bottom to top) were added to cuvettes. For the TrxR reduction assay, $0.2 \mathrm{mM}$ $\mathrm{NADPH}, 25 \mu M \operatorname{Trx} 2-\mathrm{S}_{2}$, and indicated amounts of rrTrxR (the dotted lines) were added to cuvettes, the absorbance at $340 \mathrm{~nm}$ was followed, and the linear part of the reactions was used to determine the reaction rates. (D) Conditions were the same as that of (C), except that $10 \mathrm{~m} M$ GSH was used in the Grx2 reduction assay. GR, glutathione reductase; Grx, glutaredoxin; rrTrxR, recombinant rat TrxR1; GSH, glutathione; NADPH, nicotinamide adenine dinucleotide phosphate; Trx, thioredoxin; TrxR, thioredoxin reductase; urea-PAGE, urea-polyacrylamide gel electrophoresis.

GSH alone is close to that of $3 \mathrm{n} M$ TrxR. The addition of 0.05 and $0.2 \mu M$ Grx 2 increased the rates to be comparable to the activities of 4.7 and $7 \mathrm{n} M$ TrxR, respectively.

\section{Overexpression of Grx2 in HeLa cells provides protection against TrxR inhibitors}

TrxR is the native reductant for Trxs, with very high catalytic efficiency. However, both the cytosolic and mitochondrial forms of TrxR possess a super active selenocysteine that is very sensitive to inactivation by electrophilic compounds $(35,44)$. Upon extensive inactivation of TrxR, Trx will not be reduced effectively, and increased levels of oxidized Trx will result in cell death. As we found that the Grx 2 system could reduce Trx 2 and Trx 1 , one would expect that the overexpression of Grx2 will rescue cells from TrxR inhibitors. Two Grx2 stable transfected HeLa cell lines were used, one with Grx 2 overexpression in the mitochondria (M-Grx2 HeLa cells) and the other with Grx 2 overexpression in the cytosol/nucleus (C-Grx2 HeLa cells). Here, we used auranofin (AF) and 4-hydroxynonenal (HNE) in the treatment of the three HeLa cell lines. AF is a well-known TrxR inhibitor, which is lipophilic and can permeate through biological membranes $(10,39)$. HNE is an end product of lipid peroxidation and a potent inhibitor of $\operatorname{TrxR}(13)$, and the treatment of cells with $\mu M$ range of HNE induces both mitochondrial and cytosol oxidative stress (1). Figure 3A shows the viabilities of the cell lines treated with 4-12 $\mu \mathrm{M}$ AF for $3 \mathrm{~h}$. The viability of wild-type (WT) HeLa cells decreased to $61 \%-41 \%$, whereas C-Grx 2 HeLa cells and especially M-Grx2 HeLa cells are less susceptible. Treatment of the three cell lines with 10-80 $\mu M$ HNE (Fig. 3B) resulted in a similar profile as those treated with $\mathrm{AF}$, with even higher resistance in M-Grx2 HeLa cells. Compared to WT cells, MGrx2 HeLa cells have higher viability in all HNE concentrations tested. C-Grx2 HeLa cells showed significant resistance only in the higher HNE concentrations $(40 \mu M$ and $80 \mu M$ ) and not as resistant as the mGrx2 HeLa cells. These results indicate that Grx2 overexpression either in the mitochondria or in the cytosol may protect cells from TrxR inhibitor. However, the rescuing effect was more profound with the overexpression of $\mathrm{Grx} 2$ in the mitochondria.

\section{Grx2 overexpression protects Trx2 and Trx1 from oxidation in HeLa cells}

To detect the evidence that Grx 2 reduces $\operatorname{Trx} 2$ and Trx 1 in vivo, we analyzed the redox state of $\operatorname{Tr} 22$ and $\operatorname{Trx} 1$ in the 
A
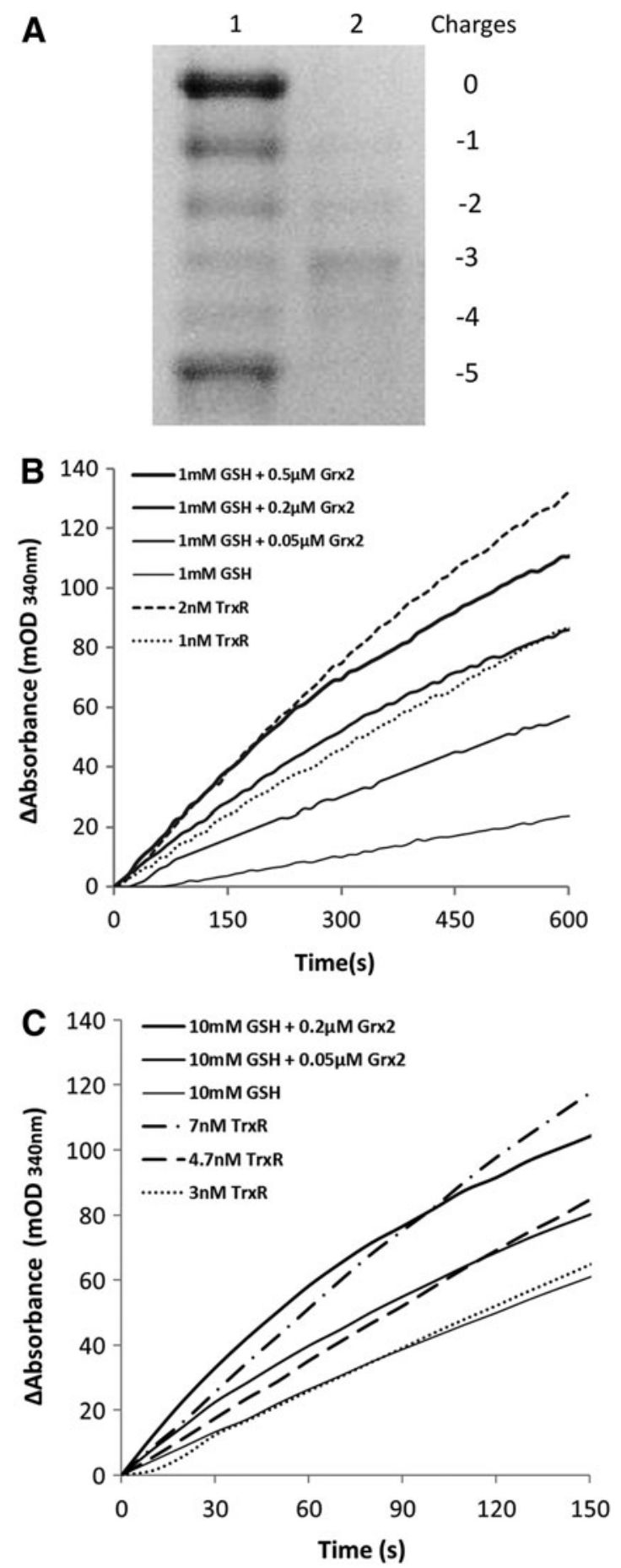

FIG. 2. The reduction of Trx1 by Grx2 system. (A) Trx $1-S_{2}$ was prepared as described in the Materials and Methods section and confirmed by redox urea-PAGE. Lane 1: mobility standard. Lane 2: Trx1-S 2 . (B) For the Grx2 reduction assay, $6 \mu \mathrm{g} / \mathrm{ml} \mathrm{GR}, 0.2 \mathrm{~m} M \mathrm{NADPH}, 1 \mathrm{~m} M \mathrm{GSH}$, $25 \mu M \operatorname{Trx} 1-\mathrm{S}_{2}$, and increasing amounts of Grx2 (the solid lines thickening from bottom to top) were added to cuvettes. For the TrxR reduction assay, $0.2 \mathrm{~m} M \mathrm{NADPH}, 25 \mu M$ Trx $1-\mathrm{S}_{2}$, and indicated amounts of rrTrxR (the dotted lines) were added to cuvettes, the absorbance at $340 \mathrm{~nm}$ was followed, and the linear part of the reactions was used to determine the reaction rates. (C) Conditions were the same as that of (B), except that $10 \mathrm{~m} M$ GSH were used in the Grx2 reduction assay.
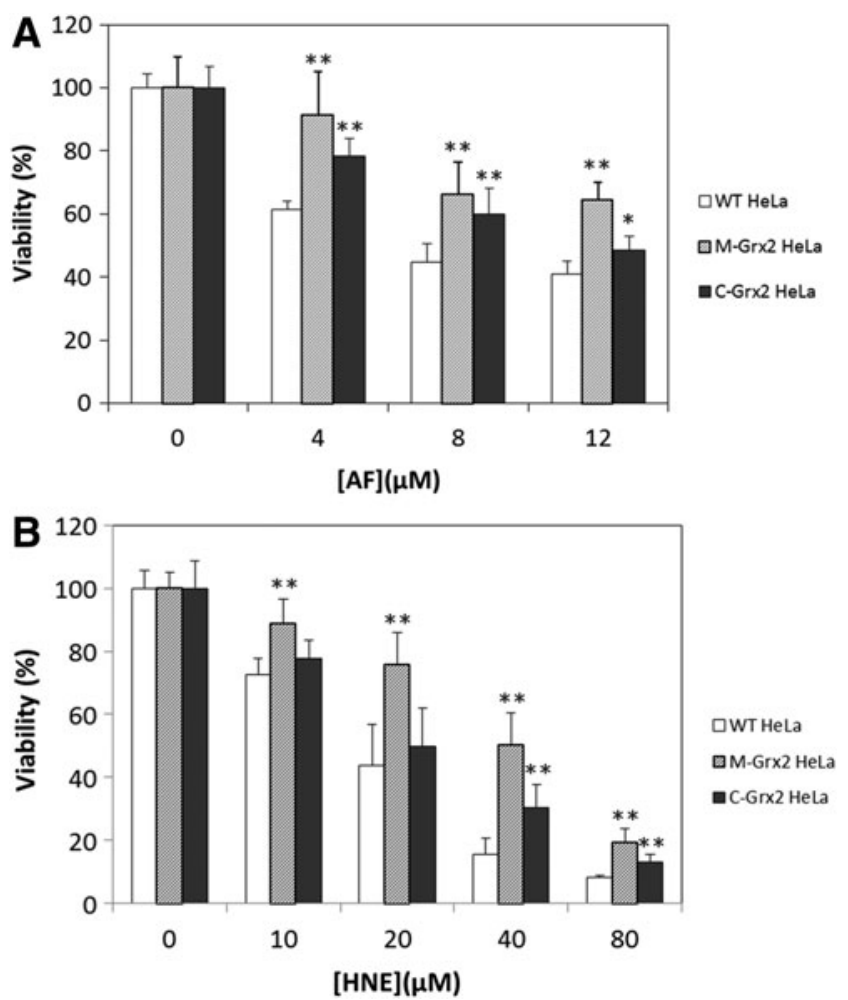

FIG. 3. Effects of AF and HNE treatment on the viabilities of WT and Grx2 overexpressing HeLa cells. WT, M-Grx2, or C-Grx2 HeLa cells were treated with the indicated concentrations of AF for $3 \mathrm{~h}$ (A) or HNE for $20 \mathrm{~h}$ (B). After treatment, the cell viability was measured with the MTT assay. Error bars show mean \pm S.D. $n=4$. $* * p<0.01$; ${ }^{*} p<0.05$, Student's $t$-test, treated cells versus control. AF, auranofin; HNE, 4-hydroxynonenal; WT, wild type.

HNE-treated WT, M-Grx2 and C-Grx2 HeLa cells, using a redox-state western blot analysis. Figure 4A shows the redox states of Trx2. The bands with -2 mobility represent fully reduced Trx2. Oxidation of 1 thiol by forming a mixed disulfide with a substrate shifts the band upwards to the -1 mobility, whereas the bands with 0 mobility represent the fully oxidized form of Trx2. Differences in the total amount of Trx were observed among the lanes. This could be resulted from the loss of total protein content during the experimental process. However, as the total protein amount does not affect the relative ratios of different redox forms within the sample, these results can be used to analyze the redox states of Trx. The fractions of different redox forms of Trx 2 in each cell lysate are shown in Figure 4B. In all the three cell lines without treatment, about $60 \%$ of Trx 2 was fully reduced. After treatment with $40 \mu \mathrm{M}$ HNE for $20 \mathrm{~h}$, the WT HeLa cells had about $50 \%$ of its $\operatorname{Trx} 2$ in the fully oxidized form, $23 \%$ in the one cysteine oxidized form, leaving only about $28 \%$ in the reduced form. On the contrary, the redox profile of $\operatorname{Trx} 2$ did not show an obvious change in the M-Grx2 cells, showing that overexpression of Grx 2 in the mitochondria had prevented Trx 2 from oxidation to a great extent. In the C-Grx2 cells treated with HNE, about half of Trx 2 were oxidized, less than in the WT cells, indicating that the overexpression of Grx 2 in the cytosol also has some effect in the prevention of Trx 2 oxidation, probably by attenuating overall oxidative stress. 

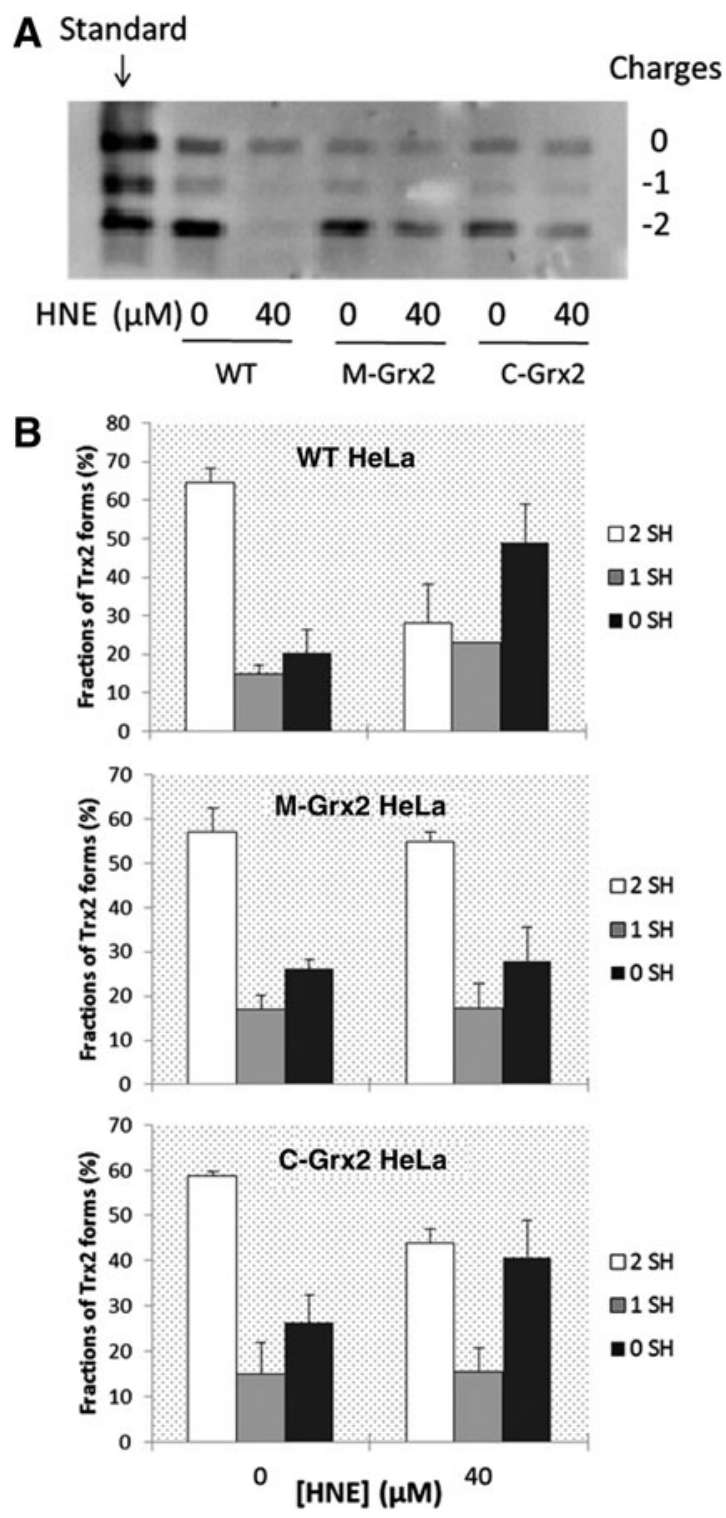

FIG. 4. Redox state of cellular Trx2 before and after HNE treatment. (A) WT, M-Grx2, or C-Grx2 HeLa cells were treated with or without $40 \mu M \mathrm{HNE}$ for $20 \mathrm{~h}$, and the redox state of Trx 2 was detected using a redox western blot analysis. (B) The intensity of each band in (A) was quantified by using the Quantity One software (Bio-Rad). For each cell lysate, the sum of intensity of bands with all three mobilities was set as $100 \%$, and the fraction (\%) of each band (redox form of Trx2) was calculated. Error bars show mean \pm S.D. based on two independent experiments.

Figure 5A shows the redox states of Trx1. Like Trx2, in all three cell lines of resting state, the fully reduced form represents the largest part of $\operatorname{Trx} 1$, whereas their responses to HNE treatment are very diverse: In the WT cells, treatment with HNE caused a dramatic decrease of reduced form of Trx1 and a great increase of the highly oxidized forms. Distinctively, the C-Grx 2 cells only had a slight decrease of the reduced form and a small increase of the 2-SH form, indicating that Grx2 overexpression in the cytosol had protected Trx 1 from oxidation. In the M-Grx 2 cells treated with $\mathrm{HNE}$, there was a small increase of the one cysteine oxidized form and the activate site disulfide form of Trx1, but not obvious increase of the highly oxidized forms.

\section{Grx2 knockdown causes decreased viability in TrxR inhibitor-treated cells}

To further explore the in vivo evidence for the backup role of Grx 2 for TrxR, we have used siRNAs specific for the mRNA of human Grx 2 to knockdown Grx 2 in the HeLa cells. After 2 days of transfection, the cells were assayed for Grx 2 levels by

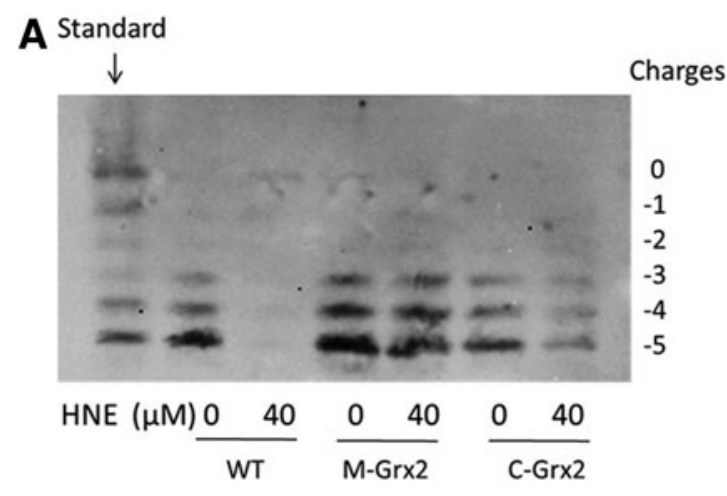

B
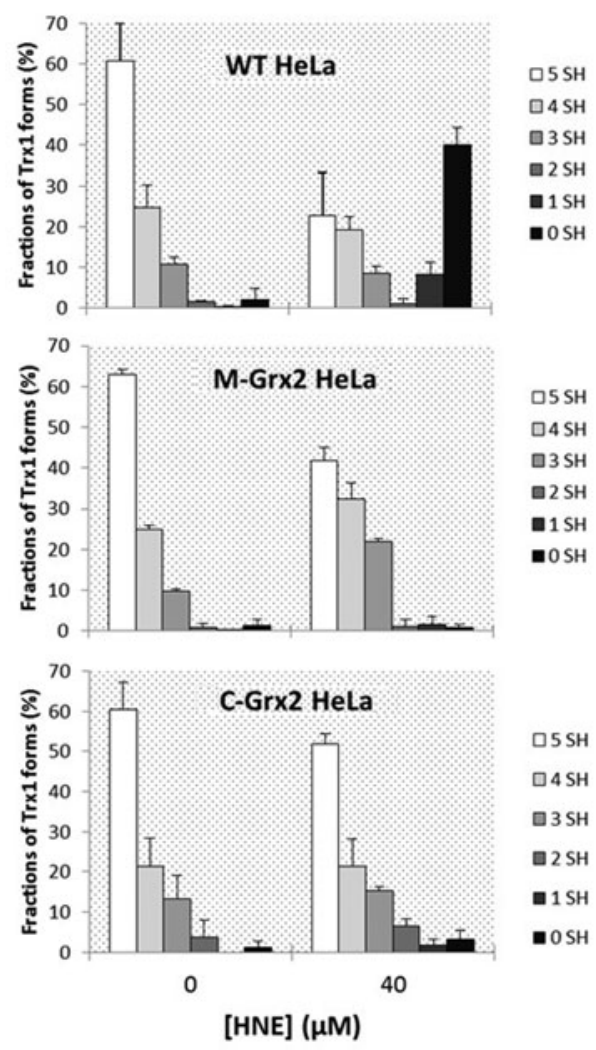

FIG. 5. Redox state of cellular Trx1 before and after HNE treatment. (A) WT, M-Grx2, or C-Grx2 HeLa cells were treated with or without $40 \mu M \mathrm{HNE}$ for $20 \mathrm{~h}$, and the redox state of Trx1 was detected using a redox western blot analysis. (B) The intensity of each band in (A) was quantified by using the Quantity One software (Bio-Rad). For each cell lysate, the sum of intensity of bands with all six mobilities was set as $100 \%$, and the fraction (\%) of each band (redox form of Trx1) was calculated. Error bars show mean \pm S.D. based on two independent experiments. 

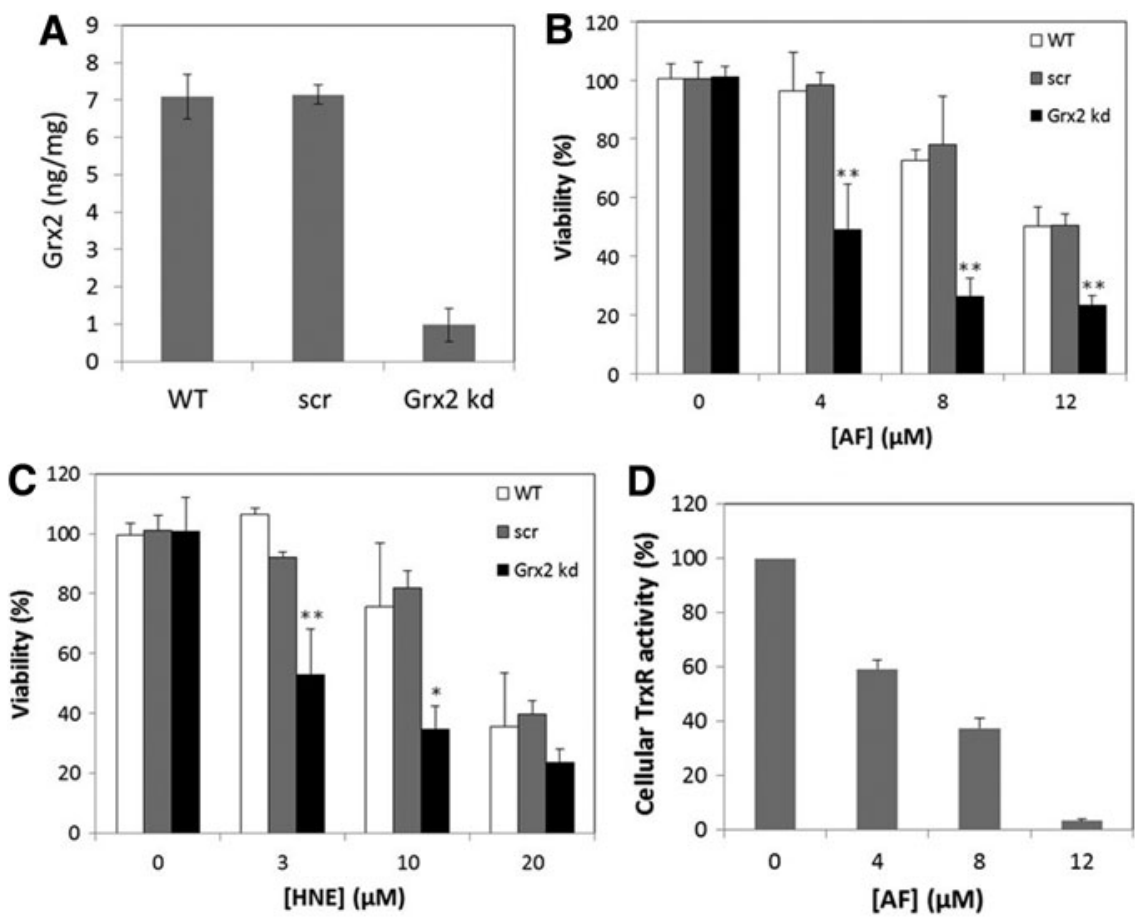

FIG. 6. Viability of WT, scr-siRNA-transfected, and Grx2 knockdown HeLa cells. (A) Levels of Grx2 in WT cells, cells treated with an unspecific scr-siRNA (scr), and cells treated with a specific Grx2 siRNA (Grx2 kd). The levels were determined by ELISA as described in the Materials and Methods section. After treatment with $\mathrm{AF}$ for $1.5 \mathrm{~h}(\mathbf{B})$ or HNE for $20 \mathrm{~h}$ (C), the cell viability was determined by the MTT assay. (D) After treatment with AF for $1.5 \mathrm{~h}$, TrxR activity was determined with the fluorescent insulin assay. Error bars show mean \pm S.D. $n=4 . \quad * * p<0.01$; ${ }^{*} p<0.05$, Student's $t$-test, treated cells versus WT control.
ELISA. As shown in Figure 6A, the Grx2 siRNA was effective in decreasing Grx 2 protein levels (to $\sim 10 \%$ of WT control). The transfection with a control of unspecific scrambled (scr) siRNA had no effect on Grx2 levels. The WT, scr-siRNA, and Grx2 siRNA-transfected cells were then subjected to the treatment with AF for $1.5 \mathrm{~h}$ or $\mathrm{HNE}$ for $20 \mathrm{~h}$ and assayed for cell viability. As shown in Figure 6B and C, the Grx2 knockdown cells showed a highly increased sensitivity to both AF and HNE.

To know the extent of TrxR inhibition that is required for Grx2 knockdown to show its effect, we have treated the cells with the same series of concentrations of AF as that in the viabilities assays and assayed the cellular TrxR activities. As shown in Figure 6D, $1.5 \mathrm{~h}$ treatment with $4-12 \mu \mathrm{M}$ of $\mathrm{AF}$ decreased the TrxR activity to about $60 \%-5 \%$ of the original level. These results show that when TrxR activity is diminished to $60 \%$ or lower, the knockdown of Grx 2 will bring more damage to the cells, probably due to the loss of backup effect of Grx2 in reducing Trxs.

\section{Grx2 knockdown causes increased Trx oxidation in TrxR inhibitor-treated cells}

Redox western blot were used to identify the redox state of Trx2 and Trx 1 in the WT control, unspecific src-siRNAtransfected, and Grx 2 knockdown cells. As shown in Figure 7, compared to the control or src-siRNA-transfected cells, the Grx2 knockdown cells had a slight increase of both oxidized Trx 2 and Trx 1 . Treatment with $10 \mu M$ HNE for $20 \mathrm{~h}$ caused a mild increase of oxidized Trx 2 and Trx 1 in the WT control and src-siRNA-transfected cells, but a dramatic increase of oxidized Trx 2 and Trx 1 in the Grx 2 knockdown cells showing that Grx 2 has the effect of protecting Trx from oxidation in vivo.

\section{Grx2 is resistant to HNE inhibition}

To investigate if HNE inhibit Grx2 activity directly, we incubated reduced Grx2 with HNE, took aliquots of the in- cubation at different time intervals, and assayed the remaining activity of Grx2. As shown in Figure 8, the activity of Grx 2 did not decrease during $3 \mathrm{~h}$ incubation with HNE. The rest of the incubation was subjected to Mass Spectrum analysis. As shown in Figure 9 A, Grx2 without modification gives a peak at $\mathrm{m} / \mathrm{z}$ value of 16150 . Five additional peaks corresponding to the addition of one to five HNE molecules to Grx2 was found, indicating that Grx2 were modified with one to five HNE molecules. To identify specific amino acid residues that are modified, the HNE-treated Grx 2 was digested

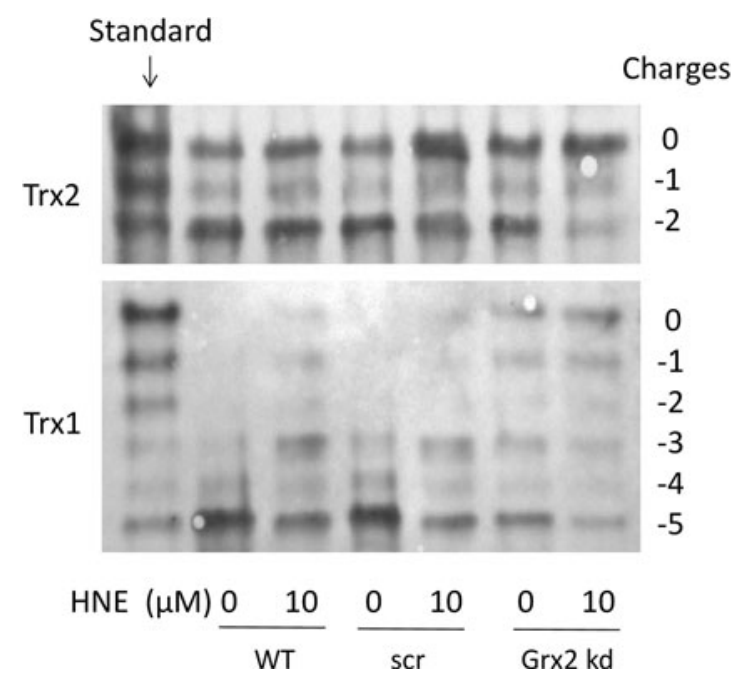

FIG. 7. Redox state of Trx1 and Trx2 in control and Grx2 knockdown cells after treatment by HNE. Cells without transfection (WT), cells transfected by an unspecific siRNA (scr), and cells transfected by a specific Grx2 siRNA (Grx $2 \mathrm{kd}$ ) were treated with or without $10 \mu M \mathrm{HNE}$ for $20 \mathrm{~h}$, and then, the redox state of Trx 1 and $\operatorname{Trx} 2$ was determined using a redox western blot analysis. 


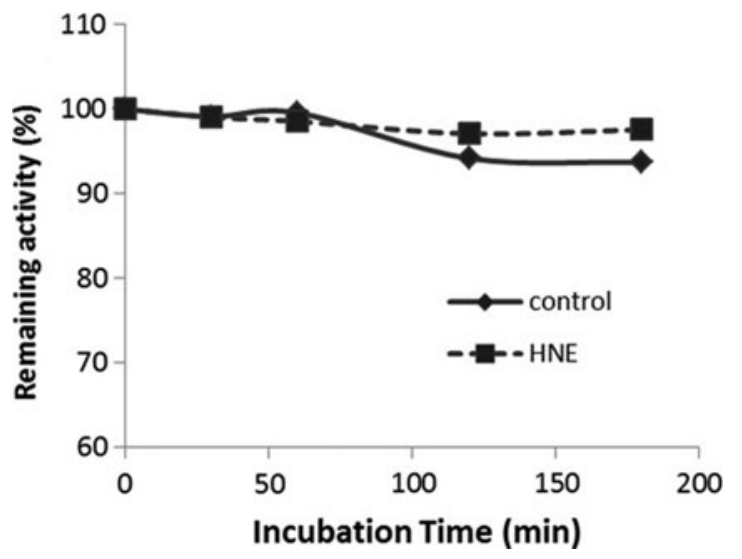

FIG. 8. Activity assay of Grx2 with/without incubation of HNE. Six micromolars of pre-reduced Grx2 was incubated with $36 \mu M$ HNE. Aliquots of the incubation were taken at indicated time intervals and assayed for the remaining activity of Grx2 with $0.7 \mathrm{~m} M$ HED as substrate. HED, 2-hydroxyethyl disulfide.

by trypsin, and the generated peptides were applied to NanoLC-MS/MS. Four peptides were identified with HNE modification (Fig. 9B-E). The sites of HNE addition were Lys74, His98, His101, and His111, respectively. One more peptide (TSCSZCTMAK, the active site Cys 37 and Cys 40 containing peptide) was found possible to be modified by HNE (Fig. 9F), with Cys 37 as the modification target. However, more spectra of the same peptide were found unmodified (spectra not shown). According to the MS data, the relative amount of modified peptide (TSC*SZCTMAK) based on integrated peptide intensities was $1.8 \%$, meaning most $(98 \%)$ of the TSCSZCTMAK peptide were not modified with HNE. The data here show that neither Cys37 nor Cys40 is a favorite target for HNE modification. Grx2 active site is relatively resistant to HNE modification, in accordance with that the activity was not lost.

\section{Discussion}

In this study, we have analyzed the protein-disulfide reductase activity of Grx2 system on cytosolic Trx 1 and mitochondrial Trx2. According to our data, under the physiological concentrations of GSH $(1-10 \mathrm{~m} M)$, Grx2 works as a reductase of $\operatorname{Tr} 22$, with the activity equivalent to about 1-10 nM TrxR. Grx2 had a similar activity toward Trx1 as that with $\operatorname{Tr} x 2$. The reducing activity of Grx 2 toward $\operatorname{Trx}$ gives the possibility for Grx2 to work as a backup for TrxR. As shown in Figure 10, in the resting cells, the reducing equivalent of NADPH goes to Trx mainly through TrxR. In the cells treated with AF/HNE, when the TrxRs are compromised and inactivated, the reducing power of NADPH may flow through a bypass composed by GR, GSH, and Grx 2 to Trxs. This hypothesis was further tested by knocking down Grx2 in the cells, where Trxs became remarkably more oxidized than in control cells when treated with same concentration of HNE (Fig. 7).

Active Trx 2 is indispensable for cell survival, as the homozygous Trx $2^{-1-}$ mouse embryonic fibroblasts (MEFs) were not viable (34). Conversely, the homozygous TrxR2 $2^{-/-}$ MEFs could be propagated (although with lower proliferation rate) (9), which means that there must be a backup system transferring electrons from NADPH to Trx2 to keep it active and functional in these cells. However, the nature of the backup system was unknown and to be identified. Interestingly, the TrxR2 ${ }^{-1-}$ cells but not the WT cells died when subjected to GSH depletion (9), implying the importance of GSH for the backup system. But the mechanism was not clear. Based on our finding that Grx2 system has the ability to enzymatically catalyze the reduction of Trx2 (Fig. 1), it is very likely that Grx 2 had worked as the electron donor for Trx 2 in the TrxR2 ${ }^{-1-}$ cells, and the cutoff of electrons from both TrxR2 and Grx 2 system resulted in cell death, as has also be seen in our study with the combination of TrxR inhibitor and Grx2 knockdown. These results implied that natural abundance of Grx2 may work as an alternative reductase for Trx 2 in vivo. To date, no candidate other than Grx 2 was found to play this role.

There are more properties of Grx2 that make it fit for a backup system. First, Grx2 protein could form dimers through a ligating iron-sulfur cluster together with two molecules of noncovalently bound GSH between the active sites of each Grx2 monomer (4). Grx2 in the dimer is catalytically inactive (24), and the iron-sulfur cluster was suggested to work as a redox sensor: During conditions of oxidative stress when free radicals are formed and the GSH pool becomes oxidized, reduced GSH may become the limiting factor for cluster coordination, leading to the dissociation of the holo-Grx2 complex, yielding enzymatically active Grx2. Thus, for Grx2, the oxidative stress plays an activating role, and the activated Grx2 will help in combating the oxidative stress. Second, Grx2 is very resistant to oxidative inactivation compared to other thiol-redox proteins (17). In our study, we have found that Grx2 is also resistant against inactivation by electrophiles like HNE (Figs. 8 and 9). The insensitiveness of Grx 2 to HNE increases its chance of protecting Trx from oxidation caused by inactivation of TrxR.

In the cytosol, the Grx1 and GSH system are very effective in protecting Trx 1 from oxidation when TrxR1 was inactivated (11). In the mitochondria, GSH cannot be synthesized de novo because of lacking of the enzyme machinery needed for GSH synthesis. Mitochondrial GSH is imported from the cytosol by specific carriers, which exhibit sensitivity to membrane dynamics (30), and mitochondrial GSH has a turnover rate more than 10-fold slower than that in the cytosol (8). Probably as mitochondria is the main generator of cellular reactive oxygen species but have a more fragile redox pool, it seems that $\operatorname{Tr} \times 2$ is more difficult to be kept reduced and functional during an oxidative insult. Overexpression of Grx2 in the mitochondria may help keeping Trx2 reduced to function in cell survival. In our study, overexpression of Grx2 in the cytosol is effective in protecting Trx1 from oxidation (Fig. 5B), but could not stop an obvious oxidation of Trx2 (Fig. 4B), and was not very effective in the prevention of cell death. Differently, overexpression of Grx2 in the mitochondria is better in protection of Trx 2 from oxidation (Fig. 4B) and also works better in preventing mitochondrial oxidative stress-mediated apoptosis. Based on these results, overexpression of Grx 2 in the mitochondria may have therapeutic potential in neurodegenerative diseases like Alzheimer's disease or Parkinson's disease, where mitochondrial oxidative stress plays a dominant role in the malfunction and apoptosis of the brain cells (43). 

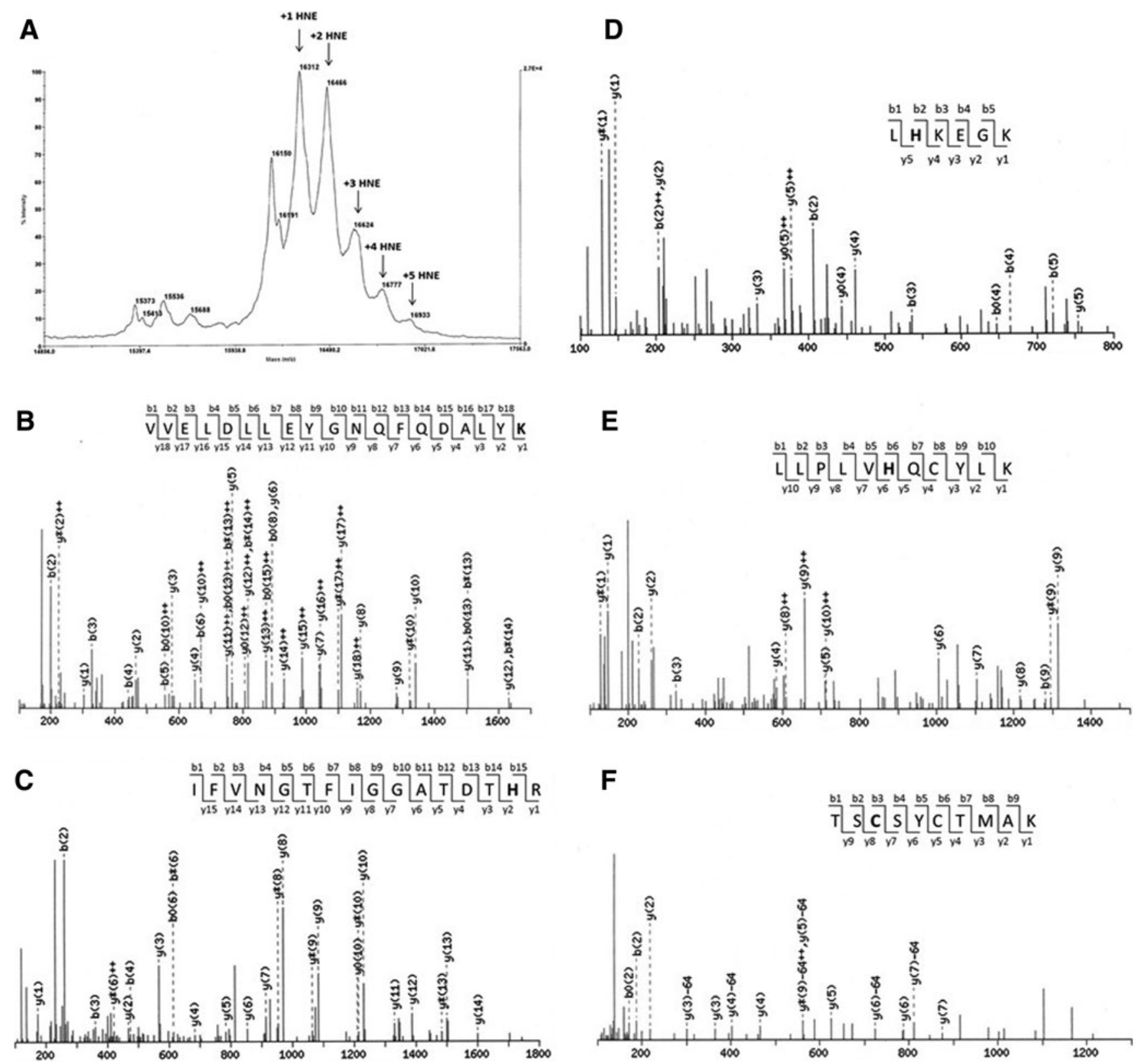

FIG. 9. Mass spectrometry analyses of HNE modification on Grx2. (A) MALDI-TOFMS of HNE-modified hGrx2. (BF) Nano-LC-MS/MS spectra of Grx2 trypsin peptides modified by HNE. The bold characters in each peptide indicate the sites of HNE addition. MALDI-TOFMS, matrix-assisted laser desorption/ionization-time-of-flight mass spectrometry.

The finding that overexpressed Grx 2 could reduce Trx 1 in the cytosol has its unique importance, as Grx 2 specifically exist in the cytosol/nucleus of a number of cancer cell lines, or testis cells, but not in the cytosol/nucleus of most normal tissue cells (27). The potential roles of cytosolic/nuclear Grx2 in the generation and progression of cancer remain unclear. The finding here may indicate a pathway for Grx2 to support cancer cell growth/survival through providing reducing equivalents to Trx1.

Conclusively, the finding in this work provides a new insight into the mechanism for Grx2 to have antioxidative and anti-apoptotic effects, that is, by catalyzing the reduction of oxidized $\operatorname{Trx} 1 / 2$. This activity is of particular importance when TrxR is inactivated by exo/endogenous electrophilic compounds. In mammalian cells, the Trx and Grx systems cannot replace each other, as both are essential for maintaining cellular redox homeostasis and cell survival. In another way, they developed cross talks within certain members from one to another system, providing backups in case if one of the systems gets paralyzed. This mutual backup may strengthen the cellular antioxidant capacity, benefiting cell survival especially under oxidative stress.

\section{Materials and Methods}

\section{Materials}

Human Trx1 and Trx1 antibody was from IMCO Ltd. Human Trx2 antibody was from Santa Cruz Biotechnology. Recombinant rat TrxR1 (rrTrxR) was a kind gift from Prof. Elias Arnér (Karolinska Institutet, Stockholm, Sweden). 
FIG. 10. Mechanism for Grx2 working as a backup for TrxR.

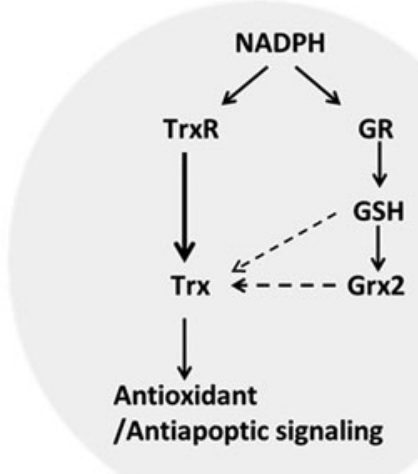

Resting cells

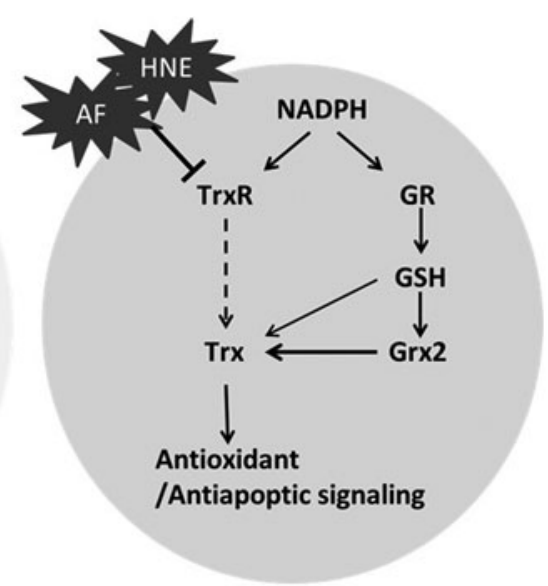

Cells treated with AF/HNE
HNE was purchased from Calbiochem. AF was form Santa Cruz Biotechnology. Yeast GR, GSH, insulin, NADPH, iodoacetic acid (IAA), and iodoacetamide (IAM) were purchased from Sigma-Aldrich. Dulbecco's modified Eagle medium (DMEM) was obtained from Invitrogen.

\section{Protein expression and purification}

Human Grx2 was expressed and purified using the autoinduction method as described in Gustafsson et al. (15) and Lundberg et al. (28). Briefly, Escherichia coli BL21CodonPlus(DE3)-RIL competentcells were transfected with pET15b hGrx2 $\Delta 41-164$. The strain was cultured in $10 \mathrm{ml} \mathrm{LB}$ medium at $37^{\circ} \mathrm{C}$ overnight. Two hundred milliliters of the auto-induction medium was inoculated with the $10 \mathrm{ml}$ overnight culture, and cells were then propagated at $18^{\circ} \mathrm{C}$ for $30 \mathrm{~h}$, harvested, and lysed by sonication. The lysates were cleared by centrifugation and filtration. Grx 2 was purified from the clarified lysates by using nickel column on Äkta purification system (GE Healthcare) equilibrated with PBS. Grx2 was eluted with $200 \mathrm{~m} M$ imidazole and desalted with NAP-25 columns equilibrated with PBS.

The E. coli BL21 (DE3) strain harboring expressing vector of His6-hTrx2 was a generous gift of Dr. Qing Cheng (Karolinska Institutet, Stockholm, Sweden). The expression and purification of hTrx 2 was conducted with the same procedures as stated above for hGrx2, except that the purified hTrx2 were desalted and buffer-exchanged to TE buffer (50 m $M$ Tris, pH7.5, $1 \mathrm{~m} M$ EDTA), instead of PBS.

\section{Preparation of the active site oxidized $h \operatorname{Tr} x 1$ and $h \operatorname{Tr} x 2$}

The human insulin is a protein of two peptide chains, the A-chain and the B-chain, linked together by two disulfide bonds. These disulfide bonds could be reduced by the active site dithiol of Trx 1 or Trx2, generating active site oxidized Trxs and reduced (separated A-chains and B-chains of) insulin. As one dithiol can only reduce one disulfide, two molar of Trxs are needed to reduce one molar of insulin. Once reduced, the insulin peptides will become insoluble, which allows the separation of the active site oxidized Trx from the precipitated insulin by centrifugation. Specifically, human Trx1/Trx2 were reduced by incubation with $10 \mathrm{~m} M$ DTT at $37^{\circ} \mathrm{C}$ for $30 \mathrm{~min}$, then excess DTT were removed by desalting on a NAP-5 Sephadex G-25 column. The reduced Trx1/2 were incubated with insulin on a molar ratio of 2:1 (Trx/ Insulin) at room temperature for $30 \mathrm{~min}$ and centrifuged at $16,000 \mathrm{~g}$ for $5 \mathrm{~min}$ to remove precipitated insulin. The supernatant containing the $\mathrm{Trx}-\mathrm{S}_{2}$ was collected, and the redox state of this product was confirmed by redox urea-PAGE, a method described in the following section.

\section{Urea-PAGE for detection of the redox state of purified Trx1/2}

The method used for the detection of Trx redox state was developed in Bersani et al. (7) and Takahashi and Hirose (40) and modified in Du et al. (11) and Ungerstedt et al. (41). To prepare mobility standards, hTrx $1 / 2$ proteins were dissolved in TEU buffer (50 $\mathrm{m} M$ Tris- $\mathrm{HCl}, \mathrm{pH} 8.2,1 \mathrm{~m} M$ EDTA, $8 M$ Urea) and incubated with $3.5 \mathrm{mM}$ DTT at $37^{\circ} \mathrm{C}$ for $30 \mathrm{~min}$ to be fully reduced. The incubation was divided into four aliquots and then treated with reagents containing varying molar ratios of IAA/IAM (concentrations in $\mathrm{m} M: 30 / 0,30 / 10$, 10/30, 0/10). The aliquots were pooled and mixed, yielding the mobility standards containing Trxs with different patterns of IAA/IAM labeling on their thiols. The Trx samples with unknown redox state were denatured with TEU buffer, and the free thiols were alkylated by IAA by adding IAA to $30 \mathrm{mM}$ and incubated at $37^{\circ} \mathrm{C}$ for $30 \mathrm{~min}$. The proteins were then precipitated by ice-cold acetone- $\mathrm{HCl}$, washed twice with ice-cold acetone- $\mathrm{HCl}$, and resuspended in TEU buffer containing $3.5 \mathrm{mM}$ DTT. After incubated at $37^{\circ} \mathrm{C}$ for $30 \mathrm{~min}$, IAM was added to a final concentration of $10 \mathrm{~m} M$ and incubated at $37^{\circ} \mathrm{C}$ for $15 \mathrm{~min}$. The treated sample and the mobility standards were then loaded on Urea-gel (12\% acrylamide [stacking gel $2.5 \%$ ] with $8 M$ urea) and separated by running at $5 \mathrm{~mA}$ for $4-5 \mathrm{~h}$ in $25 \mathrm{mM}$ Tris- $\mathrm{HCl}, 192 \mathrm{mM}$ glycine buffer. The gel was stained by Coomassie Blue, and the bands were photographed by a Bio-Rad ChemDoc XRS scanning image analysis apparatus.

\section{Enzyme activity assay}

To determine the reductase activity of hGrx 2 on hTrx $1 / 2$, a coupled enzyme reaction system was used. The system composed of $0.2 \mathrm{~m} M$ NADPH, $6 \mu \mathrm{g} / \mathrm{ml}$ GR, 1/10 m $M$ GSH, various concentrations $(0-1 \mu M)$ of $\mathrm{hGrx} 2$, and $25 \mu M$ active 
site oxidized Trx $1 / 2$ in TE buffer ( $\mathrm{pH} 7.5)$. The activity of the reaction was determined by monitoring the decrease of absorbance at $340 \mathrm{~nm}$ caused by NADPH consumption. The same system was used in determination of the reaction rates of GSH $(0-14 \mu M)$ with active site oxidized hTrx2, only without hGrx2.

The reducing activity of $\operatorname{rrTrxR}$ on $h \operatorname{Trx} 1 / 2$ was determined by adding different concentrations (0-10 $\mathrm{n} M)$ of rrTrxR to a cuvette containing $0.2 \mathrm{~m} M \mathrm{NADPH}, 25 \mu M$ active site oxidized Trx1/2 in TE buffer (pH7.5), and monitoring the change of absorbance at $340 \mathrm{~nm}$.

\section{Cell culture and viability assay}

Human cervical carcinoma HeLa cells were cultured in the DMEM medium with $1 \mathrm{mg} / \mathrm{ml} \mathrm{D}$-glucose, supplemented with $10 \%$ fetal bovine serum and $100 \mathrm{U} / \mathrm{ml}$ penicillin and streptomycin at $37^{\circ} \mathrm{C}$ in an incubator with humidified atmosphere containing $5 \% \mathrm{CO}_{2}$. The stably transfected HeLa cell lines with mitochondrial or cytosolic overexpression of Grx2 were from the construction and preparation of Enoksson et al. (12) and cultured in the same conditions as that of the WT cells.

For viability assay, the HeLa cell lines were plated in 96well plates at a density of $8 \times 10^{3}$ cells/well and cultured overnight. The medium was then changed to $200 \mu \mathrm{l}$ of fresh medium containing AF or $\mathrm{HNE}$ at the designed concentrations and treated for $1.5,3$, or $20 \mathrm{~h}$ as indicated before subjected to MTT assay: $50 \mu \mathrm{l}$ of MTT solution ( $2 \mathrm{mg} / \mathrm{ml}$ in PBS) was added to each well and incubated for $4 \mathrm{~h}$. The medium containing MTT was removed carefully. One hundred fifty microliters of dimethyl sulfoxide:glycine- $\mathrm{NaCl}$ buffer $(\mathrm{pH}$ $10.5,4: 1)$ was added to each well, and the plates were shaken for $1 \mathrm{~h}$ at room temperature. The cell viabilities were then determined by measuring the absorbance at $550 \mathrm{~nm}$. The mean value of at least 6 wells of the same treatment was used for statistical analysis.

\section{Redox Western blot of cellular Trx1/2}

To prepare mobility standards, HeLa cell lysates were denatured with urea and fully reduced with DTT and then incubated with varying molar ratios of IAA/IAM as described in the Urea-PAGE for Detection of the Redox State of Purified Trx $1 / 2$ section. To determine the redox state of Trxs in chemical compound-treated cells, the cells were washed twice with PBS, lysed in TEU buffer containing $30 \mathrm{~m} M$ IAA, and incubated at $37^{\circ} \mathrm{C}$ for $30 \mathrm{~min}$. After removing the cell debris by centrifugation, the cell lysates were precipitated by ice-cold acetone- $\mathrm{HCl}$ and washed with the same buffer. The precipitation was resuspended in TEU buffer containing $3.5 \mathrm{~m} M$ DTT and incubated at $37^{\circ} \mathrm{C}$ for $30 \mathrm{~min}$. Then, $10 \mathrm{~m} M$ IAM was added to each sample and incubated for $15 \mathrm{~min}$ at $37^{\circ} \mathrm{C}$. Proteins in the sample were separated by urea-PAGE gel and blotted to a nitrocellulose membrane (Bio-Rad). Membranes were probed with the Trx $1 / 2$ primary antibody, biotinylated secondary antibody (Dako), and streptavidin-alkaline phosphatase anti-biotin tertiary antibody (MABTECH AB) and then visualized using 5-bromo-4-chloro-3-indolyl phosphate/ nitro blue tetrazolium substrate (Sigma). The intensity of each band was quantitated with a Bio-Rad ChemDoc XRS scanning image analysis apparatus and Quantity One software (Bio-Rad).

\section{siRNA mediated knockdown of Grx2 in HeLa cells}

Negative control siRNA (scr-siRNA) and predesigned Grx2 siRNA were purchased from Qiagen. Shortly before transfection, HeLa cells were seeded in six-well plates and transfection was performed using HiPerFect Transfection Reagent (Qiagen) according to the manufacturer's protocol. Briefly, $50 \mathrm{n} M$ of the siRNAs and $12 \mu \mathrm{l}$ of Hiperfect Transfection Reagent were added to $100 \mu \mathrm{l}$ of the Optimem medium (Invitrogen). After $10 \mathrm{~min}$ of incubation, the siRNA mixtures were added to the cells. The cells were harvested after $48 \mathrm{~h}$, and the level of Grx 2 was analyzed by ELISA.

\section{ELISA of Grx2}

Quantification of Grx2 was performed by using specific sandwich ELISA as described in Lillig et al. (26). Briefly, 96-well plates were coated with affinity-purified anti-Grx2 antibodies $(2 \mu \mathrm{g} / \mathrm{ml})$ overnight at $4^{\circ} \mathrm{C}$. After blocking with bovine serum albumin (BSA), cell lysates and Grx2 standards $(0.05-50 \mathrm{ng} / \mathrm{ml})$ were added to the plate and incubated overnight at $4^{\circ} \mathrm{C}$. Biotinylated anti-Grx2 antibody $(1 \mu \mathrm{g} / \mathrm{ml})$ was used as secondary antibody, and the results were obtained by using alkaline phosphatase-conjugated streptavidin (Dako) followed by staining with p-nitrophenyl phosphate (Sigma). Quantification was carried out at $405 \mathrm{~nm}$ in a SpectraMax 340PC ${ }^{384}$ Microplate Reader (Molecular Devices).

\section{Determination of TrxR activity in cell lysates}

HeLa cells were plated at a density of $0.5 \times 10^{6}$ cells in sixwell plates in the DMEM medium. After overnight incubation at $37^{\circ} \mathrm{C}$, the cells were washed with PBS and treated with different concentrations of AF. After treatment, the cells were carefully washed with PBS twice and lysed in TE buffer (50 m $M$ Tris-HCl, pH 7.5/1 mM EDTA/protease inhibitor cocktails [Roche Diagnostics]) by sonication. The protein concentration was determined by the DC protein assay kit from Bio-Rad. TrxR activity in cell lysates was determined in 96-well plates with a fluorescent insulin assay kit (IMCO Corporation Ltd AB). Approximately $10 \mu \mathrm{g}$ of cell lysates was added to the reaction solution containing $0.25 \mathrm{mM}$ NADPH and $2.5 \mu M$ human Trx1. The reaction solutions without human Trx1 were used as background. After the reaction solutions were incubated at $37^{\circ} \mathrm{C}$ for $30 \mathrm{~min}$, fluorescent insulin was added to each well. The emission at $525 \mathrm{~nm}$ was recorded after $485 \mathrm{~nm}$ excitation using VICTOR3 Multilabel Plate Reader (PerkinElmer). TrxR activity was determined by measuring the initial velocity from a linear fluorescence increase due to the reduction of fluorescent insulin.

\section{hGrx2 activity inhibition assay}

2-hydroxyethyl disulfide (HED) assay was used to test if HNE inhibits hGrx2. hGrx2 was pre-reduced by incubation with $10 \mathrm{mM} \mathrm{GSH}$ at $37^{\circ} \mathrm{C}$ for $30 \mathrm{~min}$. Excess GSH were removed by desalting on a NAP-5 Sephadex G-25 column equilibrated with PBS. Six micromolars of pre-reduced hGrx2 was incubated with $36 \mu M$ HNE. At different time intervals, aliquots of the incubation were added to a cuvette containing TE buffer ( $\mathrm{pH} 7.5$ ) with $0.2 M \mathrm{NADPH}, 1 \mathrm{~m} M$ $\mathrm{GSH}, 6 \mu \mathrm{g} / \mathrm{ml} \mathrm{GR}$, and $50 \mu \mathrm{g} / \mathrm{ml}$ BSA. $0.7 \mathrm{~m} M$ HED was added to initiate the reaction. The activity was determined by 
monitoring the absorbance at $340 \mathrm{~nm}$. Background of HED reaction was subtracted from the reaction curves.

\section{Mass spectrometry analyses}

$6 \mu M$ pre-reduced Grx2 was incubated with $36 \mu M$ HNE for $3 \mathrm{~h}$. The excess HNE was removed by ultrafiltration, and the HNE-modified Grx2 was subjected to matrix-assisted laser desorption/ionization-time-of-flight mass spectrometry (MALDI-TOFMS) analysis (by the PK/KI facility, Karolinska Institutet). Briefly, the sample was spotted on a MALDI target plate, mixed with MALDI matrix prepared by dissolving $10 \mathrm{mg}$ of Sinapinic acid in $1 \mathrm{ml}$ of $30 \%(\mathrm{v} / \mathrm{v})$ acetonitrile/water with $0.1 \%$ trifluoroacetic acid (TFA). In the linear positive mode, HNE-modified Grx2 was identified using a MALDI-TOF mass spectrometer (Voyager-DE PRO; Applied Biosystems). The instrument was equipped with a Nitrogen laser with a Rep Rate of $3.0 \mathrm{~Hz}$. Each spectrum was the sum of 50 laser shots. The ion signal of myoglobin was used for external calibration.

To identify specific amino acid residues of Grx2 that is modified by HNE, the HNE-treated Grx 2 was reduced by DTT $\left(20 \mathrm{~m} M, 4 \mathrm{~h}\right.$ at $\left.37^{\circ} \mathrm{C}\right)$, alkylated by incubation with IAM $(40 \mathrm{mM})$ at room temperature for $2 \mathrm{~h}$ in the dark, and then digested by incubation with trypsin (4\% weight of Grx2 protein) at $37^{\circ} \mathrm{C}$ for $16 \mathrm{~h}$. The generated peptides were applied to Nano-LC-MS/MS analysis, using the Nano-EASY LC, Proxeon LTQ Velos Orbitrap (Thermo Fisher). First, the digest was dried under vacuum and then dissolved in $0.1 \%$ formic acid-5\% acetonitrile and loaded onto a prepacked $\mathrm{C} 18$ reverse phase column ( $\mathrm{PK} / \mathrm{KI}$ homemade). Next, the peptides were separated using a gradient from 5\% to $40 \%$ acetonitrile in $0.1 \%$ formic acid in $30 \mathrm{~min}$. Finally, the mass spectra were acquired in positive ion mode. Quantitative data were generated using in-house developed software (PK/KI).

\section{Acknowledgments}

We thank Lena Ringdén for excellent secretarial work, and Prof. Elias Arnér and Dr. Qing Cheng (Karolinska Institutet) for kindly providing rrTrxR, as well as Trx2 expressing plasmid. This work was supported by the Swedish Cancer Society (961), the Swedish Research Council Medicine (13X-3529), the K. A.Wallenberg Foundation, and grants from Karolinska Institutet. All MS data generation and peptide quantitation were performed at PK/KI supported by the Karolinska Institutet.

\section{Author Disclosure Statement}

No competing financial interests exist.

\section{References}

1. Abarikwu SO, Pant AB, and Farombi EO. 4-Hydroxynonenal induces mitochondrial-mediated apoptosis and oxidative stress in SH-SY5Y human neuronal cells. Basic Clin Pharmacol Toxicol 110: 441-448, 2012.

2. Anathy V, Roberson EC, Guala AS, Godburn KE, Budd RC, and Janssen-Heininger YM. Redox-based regulation of apoptosis: S-glutathionylation as a regulatory mechanism to control cell death. Antioxid Redox Signal 16: 496-505, 2012.

3. Beer SM, Taylor ER, Brown SE, Dahm CC, Costa NJ, Runswick MJ, and Murphy MP. Glutaredoxin 2 catalyzes the reversible oxidation and glutathionylation of mitochondrial membrane thiol proteins: implications for mitochondrial redox regulation and antioxidant DEFENSE. J Biol Chem 279: 47939-47951, 2004.

4. Berndt C, Hudemann C, Hanschmann EM, Axelsson R, Holmgren A, and Lillig $\mathrm{CH}$. How does iron-sulfur cluster coordination regulate the activity of human glutaredoxin 2? Antioxid Redox Signal 9: 151-157, 2007.

5. Berndt $\mathrm{C}$, Lillig $\mathrm{CH}$, and Holmgren A. Thiol-based mechanisms of the thioredoxin and glutaredoxin systems: implications for diseases in the cardiovascular system. Am J Physiol Heart Circ Physiol 292: H1227-H1236, 2007.

6. Berndt $\mathrm{C}$, Lillig $\mathrm{CH}$, and Holmgren A. Thioredoxins and glutaredoxins as facilitators of protein folding. Biochim Biophys Acta 1783: 641-650, 2008.

7. Bersani NA, Merwin JR, Lopez NI, Pearson GD, and Merrill GF. Protein electrophoretic mobility shift assay to monitor redox state of thioredoxin in cells. Methods Enzymol 347: 317-326, 2002.

8. Circu ML and Aw TY. Glutathione and modulation of cell apoptosis. Biochim Biophys Acta 1823: 1767-1777, 2012.

9. Conrad M, Jakupoglu C, Moreno SG, Lippl S, Banjac A, Schneider M, Beck H, Hatzopoulos AK, Just U, Sinowatz F, Schmahl W, Chien KR, Wurst W, Bornkamm GW, and Brielmeier M. Essential role for mitochondrial thioredoxin reductase in hematopoiesis, heart development, and heart function. Mol Cell Biol 24: 9414-9423, 2004.

10. Di Sarra F, Fresch B, Bini R, Saielli G, and Bagno A. Reactivity of auranofin with selenols and thiols-implications for the anticancer activity of gold(I) compounds. Eur J Inorg Chem 2013: 2718-2727, 2013.

11. Du Y, Zhang H, Lu J, and Holmgren A. Glutathione and glutaredoxin act as a backup of human thioredoxin reductase 1 to reduce thioredoxin 1 preventing cell death by aurothioglucose. J Biol Chem 287: 38210-38219, 2012.

12. Enoksson M, Fernandes AP, Prast S, Lillig CH, Holmgren $\mathrm{A}$, and Orrenius S. Overexpression of glutaredoxin 2 attenuates apoptosis by preventing cytochrome c release. Biochem Biophys Res Commun 327: 774-779, 2005.

13. Fang $\mathbf{J}$ and Holmgren $A$. Inhibition of thioredoxin and thioredoxin reductase by 4-hydroxy-2-nonenal in vitro and in vivo. J Am Chem Soc 128: 1879-1885, 2006.

14. Ferri A, Fiorenzo P, Nencini M, Cozzolino M, Pesaresi MG, Valle C, Sepe S, Moreno S, and Carri MT. Glutaredoxin 2 prevents aggregation of mutant SOD1 in mitochondria and abolishes its toxicity. Hum Mol Genet 19: 4529-4542, 2010.

15. Gustafsson TN, Sahlin M, Lu J, Sjoberg BM, and Holmgren A. Bacillus anthracis thioredoxin systems, characterization and role as electron donors for ribonucleotide reductase. J Biol Chem 287: 39686-39697, 2012.

16. Hashemy SI and Holmgren A. Regulation of the catalytic activity and structure of human thioredoxin 1 via oxidation and S-nitrosylation of cysteine residues. J Biol Chem 283: 21890-21898, 2008.

17. Hashemy SI, Johansson $\mathrm{C}$, Berndt $\mathrm{C}$, Lillig $\mathrm{CH}$, and Holmgren A. Oxidation and S-nitrosylation of cysteines in human cytosolic and mitochondrial glutaredoxins: effects on structure and activity. J Biol Chem 282: 14428-14436, 2007.

18. Hirota K, Matsui M, Iwata S, Nishiyama A, Mori K, and Yodoi J. AP-1 transcriptional activity is regulated by a direct association between thioredoxin and Ref-1. Proc Natl Acad Sci U S A 94: 3633-3638, 1997. 
19. Holmgren A, Johansson C, Berndt C, Lonn ME, Hudemann $\mathrm{C}$, and Lillig $\mathrm{CH}$. Thiol redox control via thioredoxin and glutaredoxin systems. Biochem Soc Trans 33: 1375-1377, 2005.

20. Johansson $\mathrm{C}$, Lillig $\mathrm{CH}$, and Holmgren A. Human mitochondrial glutaredoxin reduces S-glutathionylated proteins with high affinity accepting electrons from either glutathione or thioredoxin reductase. J Biol Chem 279: 7537-7543, 2004.

21. Kanzok SM, Schirmer RH, Turbachova I, Iozef R, and Becker K. The thioredoxin system of the malaria parasite Plasmodium falciparum. Glutathione reduction revisited. J Biol Chem 275: 40180-40186, 2000.

22. Lee SR, Kim JR, Kwon KS, Yoon HW, Levine RL, Ginsburg A, and Rhee SG. Molecular cloning and characterization of a mitochondrial selenocysteine-containing thioredoxin reductase from rat liver. J Biol Chem 274: 4722-4734, 1999.

23. Lillig $\mathrm{CH}$, Berndt $\mathrm{C}$, and Holmgren A. Glutaredoxin systems. Biochim Biophys Acta 1780: 1304-1317, 2008.

24. Lillig CH, Berndt C, Vergnolle O, Lonn ME, Hudemann C, Bill E, and Holmgren A. Characterization of human glutaredoxin 2 as iron-sulfur protein: a possible role as redox sensor. Proc Natl Acad Sci U S A 102: 8168-8173, 2005.

25. Lillig $\mathrm{CH}$ and Holmgren A. Thioredoxin and related molecules-from biology to health and disease. Antioxid Redox Signal 9: 25-47, 2007.

26. Lillig CH, Lonn ME, Enoksson M, Fernandes AP, and Holmgren A. Short interfering RNA-mediated silencing of glutaredoxin 2 increases the sensitivity of HeLa cells toward doxorubicin and phenylarsine oxide. Proc Natl Acad Sci U S A 101: 13227-13232, 2004.

27. Lonn ME, Hudemann C, Berndt C, Cherkasov V, Capani F, Holmgren A, and Lillig $\mathrm{CH}$. Expression pattern of human glutaredoxin 2 isoforms: identification and characterization of two testis/cancer cell-specific isoforms. Antioxid Redox Signal 10: 547-557, 2008.

28. Lundberg M, Johansson C, Chandra J, Enoksson M, Jacobsson $\mathrm{G}$, Ljung $\mathrm{J}$, Johansson $\mathrm{M}$, and Holmgren $\mathrm{A}$. Cloning and expression of a novel human glutaredoxin (Grx2) with mitochondrial and nuclear isoforms. J Biol Chem 276: 26269-26275, 2001.

29. Mari M, Morales A, Colell A, Garcia-Ruiz C, and FernandezCheca JC. Mitochondrial glutathione, a key survival antioxidant. Antioxid Redox Signal 11: 2685-2700, 2009.

30. Mari M, Morales A, Colell A, Garcia-Ruiz C, Kaplowitz N, and Fernandez-Checa JC. Mitochondrial glutathione: features, regulation and role in disease. Biochim Biophys Acta 1830: 3317-3328, 2013.

31. Matsui M, Oshima M, Oshima H, Takaku K, Maruyama T, Yodoi J, and Taketo MM. Early embryonic lethality caused by targeted disruption of the mouse thioredoxin gene. Dev Biol 178: 179-185, 1996.

32. Matthews JR, Wakasugi N, Virelizier JL, Yodoi J, and Hay RT. Thioredoxin regulates the DNA binding activity of NFkappa B by reduction of a disulphide bond involving cysteine 62. Nucleic Acids Res 20: 3821-3830, 1992.

33. Meuillet EJ, Mahadevan D, Berggren M, Coon A, and Powis G. Thioredoxin- 1 binds to the $\mathrm{C} 2$ domain of PTEN inhibiting PTEN's lipid phosphatase activity and membrane binding: a mechanism for the functional loss of PTEN's tumor suppressor activity. Arch Biochem Biophys 429: 123-133, 2004.

34. Nonn L, Williams RR, Erickson RP, and Powis G. The absence of mitochondrial thioredoxin 2 causes massive apoptosis, exencephaly, and early embryonic lethality in homozygous mice. Mol Cell Biol 23: 916-922, 2003.

35. Rackham O, Shearwood AM, Thyer R, McNamara E, Davies SM, Callus BA, Miranda-Vizuete A, Berners-Price SJ, Cheng Q, Arner ES, and Filipovska A. Substrate and inhibitor specificities differ between human cytosolic and mitochondrial thioredoxin reductases: Implications for development of specific inhibitors. Free Radic Biol Med 50: 689-699, 2011.

36. Rhee SG, Chae HZ, and Kim K. Peroxiredoxins: a historical overview and speculative preview of novel mechanisms and emerging concepts in cell signaling. Free Radic Biol Med 38: 1543-1552, 2005.

37. Saitoh M, Nishitoh H, Fujii M, Takeda K, Tobiume K, Sawada Y, Kawabata M, Miyazono K, and Ichijo $\mathrm{H}$. Mammalian thioredoxin is a direct inhibitor of apoptosis signal-regulating kinase (ASK) 1. EMBO J 17: 2596-2606, 1998.

38. Spyrou G, Enmark E, Miranda-Vizuete A, and Gustafsson J. Cloning and expression of a novel mammalian thioredoxin. J Biol Chem 272: 2936-2941, 1997.

39. Stanley BA, Sivakumaran V, Shi S, McDonald I, Lloyd D, Watson WH, Aon MA, and Paolocci N. Thioredoxin reductase-2 is essential for keeping low levels of $\mathrm{H} 2 \mathrm{O} 2$ emission from isolated heart mitochondria. $\mathrm{J}$ Biol Chem 286: 33669-33677, 2011.

40. Takahashi N and Hirose M. Determination of sulfhydryl groups and disulfide bonds in a protein by polyacrylamide gel electrophoresis. Anal Biochem 188: 359-365, 1990.

41. Ungerstedt J, Du Y, Zhang H, Nair D, and Holmgren A. In vivo redox state of human thioredoxin and redox shift by the histone deacetylase inhibitor suberoylanilide hydroxamic acid (SAHA). Free Radic Biol Med 53: 2002-2007, 2012.

42. Wu H, Xing K, and Lou MF. Glutaredoxin 2 prevents $\mathrm{H} 2 \mathrm{O} 2$-induced cell apoptosis by protecting complex I activity in the mitochondria. Biochim Biophys Acta 1797: 1705-1715, 2010.

43. Yan MH, Wang X, and Zhu X. Mitochondrial defects and oxidative stress in Alzheimer disease and Parkinson disease. Free Radic Biol Med 62: 90-101, 2013.

44. Zhang H, Cao D, Cui W, Ji M, Qian X, and Zhong L. Molecular bases of thioredoxin and thioredoxin reductasemediated prooxidant actions of (-)-epigallocatechin-3gallate. Free Radic Biol Med 49: 2010-2018, 2010.

45. Zhang H, Go YM, and Jones DP. Mitochondrial thioredoxin-2/peroxiredoxin-3 system functions in parallel with mitochondrial GSH system in protection against oxidative stress. Arch Biochem Biophys 465: 119-126, 2007.

Address correspondence to: Prof. Arne Holmgren

Division of Biochemistry

Department of Medical Biochemistry and Biophysics Karolinska Institute 17177 Stockholm Sweden

E-mail: arne.holmgren@ki.se

Date of first submission to ARS Central, June 25, 2013; date of final revised submission, November 12, 2013; date of acceptance, December 2, 2013. 


$\begin{aligned} & \text { Abbreviations Used } \\ & \mathrm{AF}= \text { auranofin } \\ & \mathrm{AP}-1= \text { activator protein } 1 \\ & \mathrm{ASK}-1=\text { apoptosis signal-regulating kinase } 1 \\ & \mathrm{Cys}=\text { cysteine } \\ & \mathrm{DMEM}=\text { Dulbecco's modified Eagle medium } \\ & \mathrm{GR}=\text { glutathione reductase } \\ & \mathrm{Grx}=\text { glutaredoxin } \\ & \mathrm{GSH}=\text { glutathione } \\ & \mathrm{H}_{2} \mathrm{O}_{2}=\text { hydrogen peroxide } \\ & \mathrm{HED}= \text { 2-hydroxyethyl disulfide } \\ & \mathrm{HNE}= \text { 4-hydroxynonenal } \\ & \mathrm{IAA}=\text { iodoacetic acid } \\ & \mathrm{IAM}= \text { iodoacetamide }\end{aligned}$
MALDI-TOFMS = matrix-assisted laser desorption/ ionization-time-of-flight mass spectrometry
$\mathrm{MEF}=$ mouse embryonic fibroblast $\mathrm{NADPH}=$ nicotinamide adenine dinucleotide phosphate
$\mathrm{NF}-\kappa \mathrm{B}=$ nuclear factor kappa-light-chain- enhancer of activated $B$ cells $\operatorname{Prx}=$ peroxiredoxin
PTEN $=$ phosphatase and tensin homolog
$\operatorname{Trx}=$ thioredoxin
$\operatorname{TrxR}=$ thioredoxin reductase
urea-PAGE $=$ urea-polyacrylamide gel electrophoresis $\mathrm{WT}=$ wild type

